\title{
Research on Sports Culture of Tibet Shannan Zhuo Dance
}

\author{
Zhenghong $\mathrm{Li}^{1, \mathrm{a}^{*}}$ and Gongjue Lamu ${ }^{1, \mathrm{~b}}$ \\ ${ }^{1}$ College of Sports Science, Jishou University Renmin South Road 120, Jishou City Hunan Province, \\ China \\ ajsdxgzh@126.com, ${ }^{b} 2862923557 @ q q . c o m$
}

Keywords: Shannan; Zhuo Dance; Tibet; Sports Culture

\begin{abstract}
Shannan Zhuo dance is one of the most widespread dances in Tibetan folk, which is used to pray for the Tibetan folk auspicious and to deter evil demons, and is closely linked to folk culture and secular life, is widely used in Tibetan traditional folk religious rites, major festivals and entertainment activities, has a variety of function and value.This paper, using the method of documents and materials, field research method and so on, taking Shannan Zhuo dance as the research object, explores the history, characteristics, type, value and the ecological environment of Shannan, and the logical relationship between the belief, way of life, cultural philosophy of Tibetan people in the area and Shannan Zhuo dance, and explains the rich cultural connotation and the value about Shannan Zhuo dance.
\end{abstract}

\section{Introduction}

Tibetans are good at singing and dancing since ancient times. Nature has created Tibetan people's beautiful voice, athletic physique. Long and glorious farming culture on the plateau and laboring life are the source of their dance creation. In a lot of Tibetan dances, the drum is the indispensable equipment, In their view, drum can bring good luck and joy to the person. As a result, the drums dance performances are very common. Zhuo dance spread in Shannan is a kind of waist drum dance, which is used for Tibet to deter evil spirit and pray for auspicious folk, usually performed on the opening and the closing ceremony in the major festival activities, with movement, rhythm and skills in one body, and coordinate with each other, highly unified, having infinite glamour. Shannan Zhuo dance is a more special art in traditional Tibetan dance culture and one of the most ancient dances in the world's existing traditional dance culture. After the excavation and systematization and protection and development, Shannan Zuo dance gets good inheritance and glows the vitality and vigor again. On May 20, 2006, Shannan Zhuo dance was listed in the first batch of state-level non-material cultural heritage list upon the approval of the state council. Shannan Zhuo dance shew in Shanghai world expo's "Tibet week". In 2011 China central television (CCTV) Lantern Festival party, Shannan Zhuo dance "auspicious drum rhyme" also won the high praise. After thousands of years of vicissitudes, Shannan zhuo dance is welcoming its new spring of art.

\section{The Origin of Shannan Zhuo Dance}

Zhuo dance is called "zhuo", also known as "drum dance". Tibetan original meaning is" circle dance", "luck", "smooth sailing". For the origin of the dance, uo to now, have no definite conclusion. Therefore, we can only make some inference according to the different kinds of tales. It is said in the middle of the eighth century a.d., generation 37 Tibetan king Trisong Detsen with the help of Buddhist masters padmasambhava and so on,Tibet's first temple Sangye temple was built in the north shore of the Yarlung Zangbo River. The craftsmen have worked so hard during the day, the wall of the building was ruined by a monster in the evening. In order to confuse the ghosts and gods, padmasambhava master invited Zhuo ba seven brothers from Dabu region to dance zhuo dance to deter demons. From then on, Zhuo dance in Shannan became popular. Nowadays, most villages in Shannan have ZhuoWu teams, later this dance form gradually spread into other areas. The other legend thinks that "zhuo" 
came from King Gesar. When King Gesar came back from the battlefield, he didn't know where the queen was, so King Gesar edited "Zhuo dancing". He danced and danced, so he found his queen. From then on, "Zhuo" started to spread in the folk. From the above about "zhuo dance" legends, we can see "zhuo dance" originally came from the working life, with the development and survival of folk and ethnic and religion, totem worship in the process of evolution. The early primitive dance and primitive human labor production and then the original dance came into being. With the evolution and development of the history, Shannan Zhuo dance gradually has been accepted by the masses, and become a custom activities and festivals ritual dance, and in the national folk has gotten good protection and inheritance, become the component of the numerous Tibetan dances. And a collection of a lot of the wisdom of Tibetan people hard-working, peace, wisdom..

\section{Geographical Environment of Shannan Zhuodance}

Shannan is located on the south bank of Yarlung Zangbo River, with open terrain, fertile land, for valley granary of the south Tibet, which is considered to be one of the cradles of civilization. It is said that Rhesus Macaque's combination with Luosha Lady produced the land of the Tibetan. About four or fifty thousand years ago, the Tibetan ancestors lived in Yalong area.The people here wore the leaves and ate wild fruit in Yalong valley with a lot of birds and beasts, woods in it. After a long time, Tibetan gradually learned to make up bow, stone tools, and learned to raise animals, such as raising yaks and grow barley and other crops.From around $825 \mathrm{BC}$, the first kingdom of Tibet, Nyatri Tsanpo tubo regime, built here, developed here, which was ancient Tibetan political, economic and cultural center. From the ancient times, it has been the developed agricultural areas. So, it has become the most typical agricultural and cultural birthplace, most of all, the birthplace of arts and crafts. Thereleft many famous cultural relics, architecture, sculpture, painting, etc in the process of the formation and development of Tibetan culture and art and Shannan Zhuo dance, Shannan Guo Zhuang Dance, sorcerer 's dance of Sangye temple ablaze with its unique charm..

\section{The Characteristics of Shannan Zhuo Dance}

The Strong Characteristics of Ethnic Clothing. General drummer zhuo dance actors wear bonnets. Their hair was pleated in a queue. They wear long sleeve shirt and short sleeve jacket. The lower body are dressed in more folding aprons (Tibetan is called "hot").Behind of the body are the colorful Hada or multicolor silk. The left side of the waist tie a string of lion mouth bell, armed with eagles' feathers drumstick. The left side ties flat round drum. The head of general Arre (zhuo dance team leader or commander) wear a white mask made of goat skin, black jacket with short sleeves, wear long sleeve shirt, big fat pants (Tibetan is called "Duo lu", Ajram's clothes in Tibetan opera), waist ties string made with black and white cowhair, Tibetan call it "Ti re" in the Tibetan language. Right hand hold colorful shoulder pole with three feet long, widely referred to as the "Data". Thumb wears elephant bones, called "Xiazhe" in the Tibetan language. Thet wear boots. The individual Arre in zhuo dance wear up one to three Buddha boxes on the back. Stuck a foot long Tibetan dao on. Most of them wear colorful hadad behind the back and the waist is tied with string of bells.

The Movement Characteristics of Shannan Zhuo Dance. Zhuo dance is a kind of dance with long-handled flat drum tied in the waist, and two bent drumsticks hitting the drum. When dancing Shannan zhuo dance two people lead, one after the other. The leading dancer wears a white mask plate. The dancers wear a long plait. When the players are in a excited state, their hands hit the drums, the body move upside down, long plait rotating sweeping the floor, spectacular momentum. The players that dance Shannan zhuo dance are all men, and an old man must lead dance in front of the dancing team. The drum of Shannan Zhuo dance is oblate waist drum that is hanging at the waist, which is very big and very heavy, and is about more than ten pounds heavy. The drum of zhuo dance has two belts, one is tied around the waist of the performers, the other one is tied the performer's thigh root. So, the drum can be fixed to the left side of waist. The biggest characteristics of Shannan zhuo dance is to toss 
the braid. When dancing this dance, the dancers wear a braid that has been weaved, and must be firmly into fast knot, otherwise, it is easily thrown down because of the big movement range.

The Characteristics of the Leading Dance and Group Dance of Shannan Zhuo Dance. There are 4 to 8 leaders in a performance team. They don't carry drum. They wear a white mask. Their main task is to remind action transform order, control the speed of rhythm. Their movements are full of rhythm, posture is basically the same as that of the group, and the difficulty and strength is small. The leaders must be proficient in the whole Zhuo dance movements, order. The position was held by the staff with the performance experience. Group dancing performers are dancing while they are hitting the drums, at the same time; they toss their long hair braid into the " $\infty$ ", " $\circ$ "form. Their movements are bold and unconstrained, strong powerful, strong sense of rhythm and changeable.

The Music Features of Shannan Zhuo Dance. Zhuo dance is a kind of ethnic folk dance with strong performing color, which is the collective dance participated by many people and circle is the formation of dance. The rhythm begins slow first and then become fast and its lyrics tunes is slow, deep, solemn and solid.

\section{The Cultural Value of Shannan Zhuo Dance}

The Aesthetic Cultural Value. Dance reflects the style of a nation, which is a kind of external form of national aesthetic psychology. In the 1930s, Mr CAI Yuanpei put forward the idea of "aesthetic education substituting religion": Though dancing and singing are loved by the barbarian. With the common aesthetic consciousness of cultural inheritance, they presents a relatively stable form and habitual tendency, also became folk aesthetic consciousness with the extended and long history. Because the people in Shannan live in a common geographical environment, using a common language, having the common economic and cultural atmosphere and common psychological quality, thus they form the consciousness of the common aesthetic value. "Zhuo dance" expresses the spiritual characteristics with body language. The vivid imitation of the action of the eagle in Zhuo dance reflect the Tibetan totem worship and the beauty senses beyond the words, which combines the aesthetic consciousness with aesthetic ideal.

The Cultural Value of Fitness. In a sense, Zhuo dance is a kind of expression about cultural and artistic form and is a scientific means of sports. Owing to the rhythm of dance changes from slow to fast, dancers also make corresponding adjustment. The first stage requires the dancers to stand in their place and dance, tone is slow, with no musical accompaniment. Adagio for dance is smooth and slow, at the same time, the rhythm to dance is slow and the pace is lightsome with arrogant look. Into the second period of dance, dancers begin adagio Zhuo dance, limbs stretching continuously, this time, the body muscles and joints reach the maximum range of the activities, which regulates the cardiovascular function. The third paragraph is allegro song and dance with the most bold and unrestrained ruggedly rap, it requires the dancers to move faster, the range of the dance is big and powerful, flexible, which emphasizes the endurance quality of dancers. The fourth section, also is the last part in singing and dancing, belongs to the adagio stage, and is advantageous to relax the dancer's body. During the Allegro phase in zhuo dance, if the dancers dance properly, it can largely promote the body's cardiovascular fitness, promoting the comprehensive qualities of dancers, especially, the endurance quality. All in all, a complete set of movements is very good for human body health, is a kind of way of physical exercise being worth to be advocated.

The Value of Spreading Culture. The Chinese nation has a long history and profound cultural connotation. People pay attention to national cultural pride and more cherish their national folk art and culture. At present, the national traditional folk dance is listed into the state non-material cultural heritage protection projects. With the spread of the Tibetan dance, more and more people understand the Tibetan folk culture, rich ethnic culture is gradually receive more attention. As far as the writer know, many people in the cities in the mainland in the early morning or sunset dance Shannan Zhuo dance.

Spiritual and Cultural Value. Zhuo dance promotes the sports culture education function; 
promote the unity of all ethnic groups and cultural exchanges. Zhuo dance, as a minority dance, has a special ring formation, which lest each activists can see everyone, and let them feel they are equal psychologically. There is a strong cohesion and centripetal force. During dancing, the dancers can communicate in the language and behavior, which strengthens the relationship between each other, and the friendship between people. When the people dance Shannan Zhuo dance, some of them can't dance, so some people who can dance can act as teacher, who can teach others the skills, which can cultivate their teaching ability and is conducive to the cultivation of self-confidence, also promote the communication between the different national culture, promote cultural development and prosperity, which is conducive to the national unity.

The Cultural Value of Education. Dancing art education is an important content of school education, Shannan Zhuo dance can develop the students' ability of art appreciation and aesthetic ability. Dance education thinks: Esthetic education is not simple artistic skill training, but to arouse people's aesthetic feeling, appreciation and innovation. Due to the experience of beauty, shock and feelings, thus form a better life and the pursuit of beauty, which inspired people's goodness and wisdom, so make the students' personality achieve the comprehensive optimization. The education of beauty can make the person have the character mainstream, the aesthetic quality and the sentiment of beauty, have the ability to create beauty and to appreciate beauty. Zhuo dance emphasizes and pays attention to the harmony, mutual cooperation, and mutual feelings, build community atmosphere, cultivate excellent national culture, which is just what the modern school education needs. Shannan Zhuo dance can cultivate the students' optimistic attitude, health and elegant life attitude to overcome difficulties and the traditional virtue to care of each other, unity and love. That Shannan Zhuo dance is included in the education program of school can cultivate students' taste in the process of exercise, strengthen students' aesthetic ability and the ability to create beauty.

The Value of Knowledge Inheritance. Shannan zhuo dance plays an important role in emotional connection in Tibetan people. Shannan zhuo dance is closed linked to ethnic customs, plays an important role in the performance of the national characteristics. Shannan zhuo dance has the important value of the inheritance of folk knowledge. For example, some lyrics are about the Tibetan ancient history; Some lyrics are about praising hero, living Buddha, and the great feats of big shots in the history; Some lyrics are about praising mountains and rivers Some lyrics have knowledge of the weather, the production and the religious; Some lyrics praise the friendship and relationship between the various ethnics and teach people to learn the true, the good and the beautiful. The lyrics contains simple moral standards.

\section{Summary}

Ancient Shannan zhuo dance with unique style bears the rich cultural connotation, containing the rich social memory of Shannan society and history, which is the living fossil of ancient art and the national memory. However, facing the foreign culture shock and the sharp change of modern society, Shannan zhuo dance, like most of the national traditional folk culture, is on the brink of death. A lot of physical objects and data with historical and cultural value are destroyed or lost. Some older folk artists gradually go away, and a new generation of inheritance appears fault, which make people feel sad and worried.

\section{Acknowledgements}

The National social Science Fund(12BTY046); 2015Philosophy and Social Science Fund Project of Hunan province (15YBA318); 2015Scientific Research Key project of Hunan Province Department of Education (15A154); 2015Western philosophy and Social science Fund project of Hunan province

(15YBX037) ; 2013 Scientific Research Project of Hunan province Department of Education (13C768); 2014 Core Curriculum Group Construction Projects of General Class of Jishou University 


\section{References}

[1] Rong. Ze ren Deng Zhu, General History of Tibetan people [M], Lhasa, the Tibetan people's publishing house, 2001. Cairang Zhaxi, Some Thoughts about Zhuo Dance Teaching,

[2] Wang Xihua, Shannan “Zhuo" (Drum dance), Study of Tibetan art[J],Vol.4,1992,pp.48-49.

[3] Yang Ya, A review on the Tibetan Intangible Cultural Heritage in Lho-kha of Tibet, Journal of Sichuan University for Nationalities[J], Vol. 23, 2014,pp.22.

[4] Wang Xihua, Yun Chong, Suolang Ciren, the overview of Zhuo (Drum Dance) in Qiongjie county of Shannan, Study of Tibetan art[J],Vol.1,1996,pp.21-25.

[5] Qu Jie, Talking About "Jiuhe Zhuo Dance" of Qiongjie in Tibet and Its protection, Study of Tibetan art[J],Vol.2,2009,pp.36-42.

[6] Qu Jie, Jiuhe Zhuo Dance, China's Tibet, Vol.4, 2011, pp.50-55.

[7] Lin Daosheng, Analysis of physical training value of Shannan Qiongjie Zhuo Dan on the dancers, Artistic Windows [J], Vol.5, 2013, pp.76.

[8] Xue Kang, The artistic features of the various schools of Tibetan opera in Tibet and the origin of the white masks of Tashi Sherpa in Tibetan opera, Study of Tibetan art[J],Vol.4,2003,pp.44-52.

[9] Danzen Ciren, Tibetan opera and dance, Study of Tibetan art [J],Vol.2,2003,pp.12-16. 